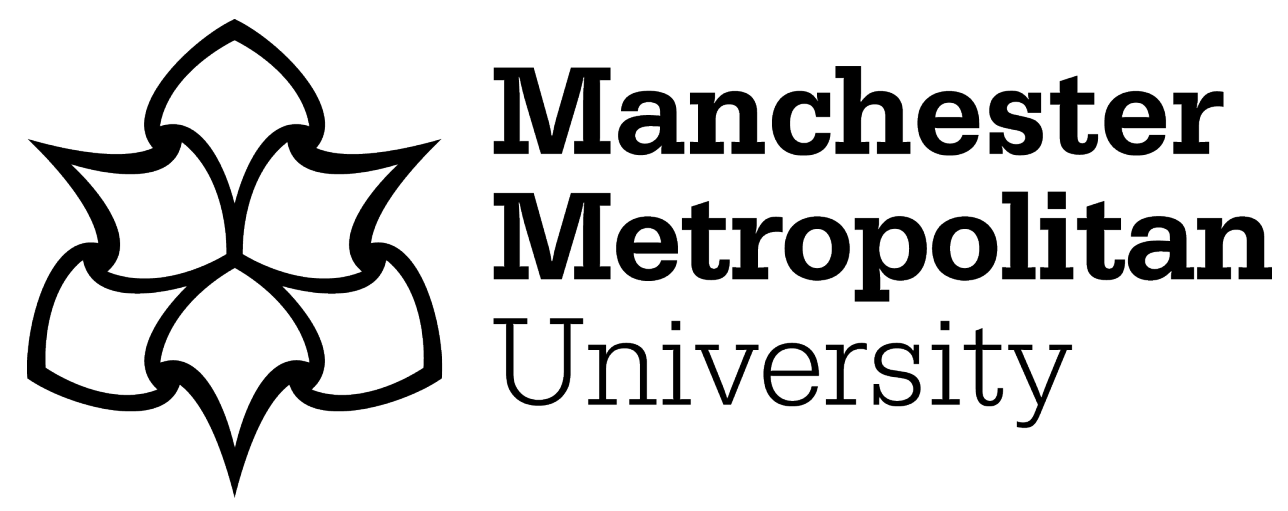

Maes, Bea, Nijs, Sara, Vandesande, Sien, Van keer, Ines, ArthurKelly, Michael, Dind, Juliane, Goldbart, Juliet ORCID logoORCID: https://orcid.org/0000-0003-1290-7833, Petitpierre, Geneviève and Van der Putten, Annette (2021) Looking back, looking forward: methodological challenges and future directions in research on persons with profound intellectual and multiple disabilities. Journal of Applied Research in Intellectual Disabilities, 34 (1). pp. 250-262. ISSN 1360-2322

Downloaded from: https://e-space.mmu.ac.uk/626716/

Version: Accepted Version

Publisher: Wiley

DOI: https://doi.org/10.1111/jar.12803

Please cite the published version 


\title{
Looking back, looking forward: methodological challenges and future directions in research on persons with profound intellectual and multiple \\ disabilities
}

Bea Maes ${ }^{\mathrm{a}}$, Sara Nijs ${ }^{\mathrm{a}}$, Sien Vandesande ${ }^{\mathrm{a}}$ Ines Van keer ${ }^{\mathrm{a}}$, Michael Arthur-Kelly ${ }^{\mathrm{b}}$, Juliane Dind $^{\mathrm{c}}$, Juliet Goldbart ${ }^{\mathrm{d}}$, Geneviève Petitpierre $^{\mathrm{c}}$, \& Annette Van der Putten $^{\mathrm{e}}$

${ }^{a}$ Catholic University of Leuven, Faculty of Psychology and Educational Sciences, Research Unit Parenting and Special Education, Leopold Vanderkelenstraat 32, box 3765, 3000 Leuven, Belgium.

${ }^{\mathrm{b}}$ University of Newcastle, School of education, University Drive Callaghan, NSW 2308, Australia

${ }^{\text {c } U n i v e r s i t e ́ ~ d e ~ F r i b o u r g, ~ D e ́ p a r t e m e n t ~ d e ~ P e ́ d a g o g i e ~ s p e ́ c i a l i s e ́ e, ~ R u e ~ S t .-P . ~ C a n i s i u s ~ 19, ~ S P C ~}$ 01 bu. 103, 1700 Fribourg, Switzerland

${ }^{d}$ Manchester Metropolitan University, Faculty of Health, Psychology \& Social Care, 53 Bonsall Street, Manchester, M15 6GX, United Kingdom e University of Groningen, Faculty of Behavioural and Social Sciences, Grote Rozenstraat 38, 9712 TJ Groningen, The Netherlands

Corresponding author: Bea Maes, bea.maes@kuleuven.be

\begin{abstract}
Within the context of the Special Interest Research Group (SIRG) on Persons with Profound Intellectual and Multiple Disabilities (PIMD), researchers often discuss the methodological problems and challenges they are confronted with. The aim of the current article is to give an overview of these challenges concentrated around six topics. These reflect the main components
\end{abstract}


RUNNING HEAD: Methodological challenges and future directions

of a study's design: (1) participant demarcation, (2) participant recruitment, (3) data collection and instruments, (4) data analysis, (5) ethics/including the 'voice' of persons with PIMD, and (6) theoretical models. Next to describing the specific challenges, possible solutions and pathways to address them are discussed. These are illustrated by recent studies by the authors and other researchers in the field.

Keywords: PIMD, PMLD, Profound Intellectual and Multiple Disabilities, Profound and Multiple Learning Disabilities, methodological challenges, future directions 
RUNNING HEAD: Methodological challenges and future directions

\section{Introduction}

In 1996, the Special Interest Research Group (SIRG) on Persons with Profound Intellectual and Multiple Disabilities (PIMD) was founded within the International Association on the Scientific Study of persons with Intellectual and Developmental Disabilities (IASSIDD) (see https://www.iassidd.org/profound-intellectual-and-multiple-disabilities/). The SIRG PIMD drew on research and publications of the previous 20 years which used a diversity of descriptors but addressed children and adults with what we now call profound intellectual (and multiple) disabilities. The founders wanted to create a platform to promote research and multidisciplinary collaboration in this domain and to build an international network for exchange and dissemination of research and good practice (Nakken \& Vlaskamp, 2002). They considered this to be necessary because of the relative absence of this specific target group in research as well as policy. More than 20 years after establishing the SIRG PIMD, it plays a pivotal role in identifying and progressing leading edge research concerning persons with PIMD, with the ultimate goal of improving quality of life and services for persons with PIMD, their families, and the professionals involved in supporting these persons.

People doing research on and with persons with PIMD are confronted with many methodological problems and challenges which have affected the progress of this field. Over the years, the research meetings of the SIRG PIMD have been a platform to discuss these methodological challenges, but also to learn about innovative ideas and good practices. The current article summarizes the main challenges that have been identified during those discussions. The aim of the article is to describe the identified challenges, structured into the different components of a study's design: (1) participant demarcation, (2) participant recruitment, (3) data collection and instruments, (4) data analysis, (5) ethics/including the 'voice' of persons with PIMD, and (6) theoretical background. All challenges are closely related to the specific characteristics and vulnerabilities of the target group. Though they are discussed in six separate 
RUNNING HEAD: Methodological challenges and future directions

themes for the sake of clarity, it is important to take into account that they are inherently intertwined. For example, a lack of appropriate or adapted instruments to measure cognitive functioning leads to difficulties in demarcating the target group. Where applicable, the article describes the links between the different paragraphs.

An overview of the identified challenges can be found in Table 1. After describing each challenge, possible solutions and pathways to address them will be discussed. This is illustrated by recent research projects of the authors and other colleagues, without intending to give a systematic overview of call research within the PIMD field. For many of the problems, there is no ideal solution available. Therefore, for each topic the remaining questions and issues or reflections for further research will be clarified. The article provides researchers on persons with PIMD with a framework, with the expectation that this can nurture and facilitate further discussions.

\section{Participant demarcation}

In different countries, different terminologies are used to indicate the target group, such as persons with complex support needs, persons with profound intellectual disabilities, persons with multiple disabilities, persons with profound intellectual and multiple disabilities (PIMD), persons with profound and multiple learning disabilities (PMLD), persons with severe intellectual and motor disabilities etc. (for an overview see Bellamy, Croot, Bush, Berry, \& Smith, 2010; Nakken \& Vlaskamp, 2007). Therefore, when conducting systematic reviews, it remains important to include different terms to refer to the target group in the search strategy. A Scopus search from 2007-2019 identified 116 relevant papers using the term 'PIMD', 67 using the term 'PMLD', and a small number of other terms such as profound intellectual disability. There are some geographical characteristics evident, with papers from the U.K. mostly using PMLD, where this term is used in educational and social policy documents; 
RUNNING HEAD: Methodological challenges and future directions

whereas PIMD is used extensively across the rest of Europe. Increasingly, from 2012, there are indications that authors are choosing to use both PIMD and PMLD.

Moreover, the same terms are often applied to persons with heterogeneous capabilities and limitations. This makes comparison of study results difficult, and creates misunderstandings in interpreting data about the target group. The publication by Nakken and Vlaskamp (2007) was an important milestone with regard to this challenge. They acknowledged that persons with PIMD form a heterogeneous group, but proposed a consensus definition: "individuals with PIMD have two key defining characteristics: (a) profound intellectual disability and (b) profound motor disability. They also have a number of additional severe or profound secondary disabilities or impairments" (Nakken \& Vlaskamp, 2007, p. 85). Bellamy et al. (2010), however, concluded from their analysis that, in almost all definitions used in the research literature, two elements are crucial: the profound intellectual disability on the one hand, and the multiplicity of disabilities including sensory and/or physical impairments and health problems on the other hand. The distinction between the foregrounding of the profound motor disability in Nakken and Vlaskamp's definition and the more general sensory and/or physical impairments and health problems in Bellamy's analysis persists and is still evident in research literature. This leads to a continuous tension between trying to strictly demarcate the target group versus recognizing the idea of a spectrum of (dis)abilities. Therefore, it is recommended that publications of empirical studies rely not only on a general term, but describe in detail the characteristics of the participants, referring to their level of cognitive functioning, their level and ways of communicating, their motor and sensory (dis)abilities and their health problems. This probably best meets the large heterogeneity within the target group.

Some scholars have criticised the emphasis on limitations in the current definition of the target group. They plead for a definition that refers to the high and lifelong support needs of these children and adults or to their capacities and strengths (e.g., Lebeer, Nijland, Grácio, \& 
RUNNING HEAD: Methodological challenges and future directions

Schraepen, 2017). Although there is no doubt that persons with PIMD have considerable capacity for learning and relating to other people, we would argue that the currently used definitions (Bellamy et al., 2010; Nakken \& Vlaskamp, 2007) bring more clarity and coherence in the demarcation of the target group for research purposes.

An additional problem relates to the operationalization and assessment of the core elements in the definition. Profound intellectual disability is generally defined as an estimated IQ below 20-25 or as a developmental age below 2-3 years in adults (Berk, 2010; Ware, 1994; WHO, 2018). In the target group, however, standardised IQ-tests are not applicable for a valid estimation of their level of intellectual capacity, especially considering their impeding motor and sensory limitations. Specific instruments that were applied to assess aspects of cognitive functioning in the group of persons with severe and profound ID, such as the Uzgiris and Hunt scales of sensorimotor development (1975; 1987; Dunst, 1980) and the Behaviour Assessment Battery (BAB; Kiernan \& Jones, 1977) are out of print. Some recent projects may fill in this gap, for example the Dutch adaptation of the BAB (Behaviour Assessment Scales, Vlaskamp, Van der Meulen, \& Smrkovsky, 1999) is being revised (Wessels, Paap, \& van der Putten, submitted) and a new scale to evaluate cognitive functioning in persons with PIMD has been developed in France (Scelles \& Petitpierre, 2013).

One way to overcome the above-mentioned challenge, is to use the qualitative description of profound ID as proposed in the DSM-V (APA, 2013, p. 33): (1) Conceptual skills generally involve the physical world rather than symbols (e.g., letters, numbers). Some visualspatial skills, such as matching and sorting, may be acquired with practice. (2) The person has limited understanding of symbolic communication. He may understand some simple instructions and gestures. Communication is usually through nonverbal, non-symbolic means. Relationships are usually with family members and other familiar people. (3) The person is dependent on others for all aspects of physical care, health and safety, although he may 
RUNNING HEAD: Methodological challenges and future directions

participate in some aspects of self-care. Some show challenging behaviours, such as self-injury. Parents or professionals can be asked to judge the level of functioning based on these descriptions.

Another possibility is to use general developmental scales. Persons with profound ID are described as functioning at the sensorimotor level, which refers to a developmental age between 0 and 24 months (Hogg, Juhlberg, \& Lambe, 2007; Kraijer \& Plas, 2007). In young children, the developmental age should be considered in relation to their chronological age, to have an indication of the degree of their developmental delay (e.g., Vandesande et al., 2019b; Van keer et al., 2017). The use of developmental scales for older children or adults should be treated with caution. Although this may give a global indication of the person's abilities on several developmental domains, the calculation of the developmental age is not always based on clear guidelines, the content of the scales is not adapted to the specific life situation of persons of older age, and the scales are based on typically developing children, possibly neglecting atypical aspects of development in persons with PIMD.

To operationalise the criterion of profound motor disability, the Gross Motor Function Classification System - Expanded and Revised (GMFCS-E\&R) (Palisano, Rosenbaum, Bartlett, \& Livingston, 2007) can be useful. The GMFCS-E\&R is a standardised 5-level system to classify gross motor functioning in persons with cerebral palsy $(\mathrm{CP})$ aged from 0 to 18 years, with an emphasis on functional daily self-initiated movements. In several studies (e.g., Dhondt, Van keer, van der Putten, \& Maes, 2019; Van keer et al., 2017), levels IV and V were used as an indicator of a profound motor disability, and additionally, level III when the child is less than 2 years old, since combining level III, IV and V has a better predictive value at this young age (Gorter, Ketelaar, Rosenbaum, Helders, \& Palisano, 2009).

Although visual and/or auditory impairments are frequent in persons with PIMD (Evenhuis, Theunissen, Denkers, Verschuure, \& Kemme, 2001; van Timmeren, van der Putten, 
RUNNING HEAD: Methodological challenges and future directions

van Schrojenstein Lantman-de Valk, van der Schans, \& Waninge, 2016), several authors have noted the lack of reliable assessment instruments to measure the level and the nature of sensory deficits in this target group (Nijs, Maes, \& Schouten, 2019; van den Broek, van Ramshorst, \& Deen, 2006). Traditional assessment procedures, which are often based on verbal responses and active participation of the person, are difficult to apply in the group of persons with PIMD. Recent projects, such as the development of the Dutch Visual Assessment Scale (Steendam \& Wallroth, 2018) to assess cerebral visual impairments in persons with PIMD may fill this gap. Potentially, eye tracking technology may also deliver new possibilities in objectively assessing the visual functioning of persons with PIMD (Kooiker et al., 2016).

\section{Participant recruitment}

Another challenge is the recruitment of participants. This often results in small sample sizes, causing difficulties in using generally accepted statistical measures (cf. section 4), in giving a reliable answer to the research questions, and in getting new research funding. This might tempt researchers to slice their data to publish as much as possible using one dataset (Kirkman \& Chen, 2011). Various reasons can be described to explain these small sample sizes.

First, the characteristics of persons with PIMD lead to small sample sizes. The specific combination of a profound intellectual disability and motor and/or sensory disabilities results in low prevalence rates of PIMD (Hatton, Glover, Emerson, \& Brown, 2016; Vugteveen, van der Putten, \& Vlaskamp, 2014). This means that a small number of participants with PIMD can still be considered as a rather large group in comparison with the total population. In addition to low prevalence rates, often very young children have not yet received an official diagnostic label of PIMD. At this young age, it is difficult to describe the targeted group for parents and professionals (Dhondt et al., 2019). Often, these children and their families are not yet in the professional circuits or services from which researchers recruit. Second, persons with PIMD 
RUNNING HEAD: Methodological challenges and future directions

may experience significant physical and/or mental health problems which could hinder participation in research, particularly in longitudinal studies, and may increase drop-out rates (Cooper et al., 2007; Poppes, van der Putten, \& Vlaskamp, 2010; van Timmeren et al., 2016). Third, there is a limited number of recruitment channels available to find persons with PIMD for research, which may hinder randomization and may lead to selection bias (e.g., Neerinckx et al., 2014; Van keer et al., 2017). Participant recruitment is primarily carried out through professionals and care or voluntary sector organisations that support persons with PIMD. However, since there is a limited number of organisations with this specific expertise, these recruitment channels are easily over-subscribed. In addition, professionals have a busy work schedule, meeting the intensive and specific support needs of persons with PIMD and dealing with the myriad of new trends in policy and practice (van der Putten, ter Haar, Maes, \& Vlaskamp, 2015). Hence, time and energy to contribute to research is not often seen as a priority. A fourth reason for small sample sizes in PIMD research is that researchers struggle with reaching and motivating families who may wish to participate (Luijkx, van der Putten, \& Vlaskamp, 2017; Vandesande et al., 2019a). Especially for families with young children or when intensive or intrusive data collection measures are needed (such as video-recordings in the home situation), this issue holds true, for example, due to time constraints or emotional burden in these families. In some cases, professionals act as gatekeepers, deciding for families that participation (and even inviting their participation) would be too demanding. Contributing to non-participation, parents and professionals may have high expectations with regard to the immediate return of research findings, which cannot always be met. Often, the immediate return, especially on an individual level, is fairly small since conducting sound research takes time and an individual report of research results does not always provide a valid representation. A fifth reason behind non-participation, especially in intervention studies, is an underestimation of the learning potential of persons with PIMD (e.g., Bossink, van der Putten, Waninge, \& 
RUNNING HEAD: Methodological challenges and future directions

Vlaskamp, 2017; Nijs, Vlaskamp, \& Maes, 2018). When parents or professionals are not convinced of the abilities of persons with PIMD to learn new behaviours, they may not be inclined to participate in these studies. Since researchers do not always get a detailed insight into the reasons for non-participation, it is challenging for them to take targeted actions to promote participation.

These issues have, in turn, fuelled strategies to increase research participation of persons with PIMD, their families, and their professional caregivers. To maximise participation, researchers in the area of PIMD have invested in recruiting through websites with appealing logos and names, presentations and social media and flyers to announce new research projects. They often pay special attentionto making personal contact with possible participants (e.g. by using a photograph of the researcher). In addition, a lot of effort is given to establishing international collaborations between research centres to expand the geographic regions from which participants can be included (e.g., the OJKO-project), intensive collaborations with large parents' associations (e.g., EMB Nederland, PAMIS) and the creation of academic collaborative centres in which research centres have a structural partnership with care organisations (e.g., Multiplus, University of Leuven; Tranzo, Tilburg University; Research Centre on Profound and Multiple Disabilities, University of Groningen). Multi-site international studies open the possibility for data-sharing, but also raise the question of the availability of validated tools in different languages, sometimes even within the same country (Petitpierre, Wolf, Adler, Benz, \& Dietrich, 2007). The recruitment of participants is usually preceded by the recruitment of the facilities/schools where they live/learn. Continuous investment in good relationships between these facilities/schools and the research partners is crucial. Openness towards research may be increased in the case of participatory research (Petitpierre \& Dind, in preparation) (cf. section 3). Another strategy, that can be experienced by parents as empowering and stimulates participation, is to use parents as ambassadors to 
RUNNING HEAD: Methodological challenges and future directions

recruit their peers or to organize preliminary focus groups to determine a recruitment strategy (e.g., Sterker Samen EMB, University of Groningen).

Researchers also ensure that they translate research findings into lay terms and disseminate this knowledge through booklets, training initiatives, newsletters, infographics, social media and/or e-mail (e.g. Platform EMG, Multiplus, PAMIS). A future path which could possibly realise higher sample sizes is collaboration with other research units doing research on different target groups who experience similar problems (such as persons with severe autism, with dementia or with challenging behaviour). This is not without its challenges, however, in terms of application and generalisation.

\section{Data collection and instruments ${ }^{1}$}

Ensuring research of high quality is largely dependent on the reliability and validity of the measures that are used in quantitative studies, and similarly, on the transferability and credibility of processes in qualitative research. In this regard, research aimed at persons with PIMD is challenged by a lack of instruments that are specifically developed and evaluated for this target group. Next to using researcher-developed, but often not validated instruments (e.g., Axelsson \& Wilder, 2014; Hostyn, Daelman, Janssen, \& Maes, 2010), a common practice is to use and/or adapt instruments developed for other target groups. The frequent use of instruments originally aimed at young typically developing children (Chadwick, Buell, \& Goldbart, 2019; Hostyn, Petry, Lambrechts, \& Maes, 2011; Vandesande et al., 2019a; Van keer et al., 2017) is based on the assumption of comparable levels of functioning and developmental trajectories. However, due to the complex interplay between the cognitive, motor and/or sensory impairments of persons with PIMD, this comparability cannot be guaranteed and the person may be at risk of being underestimated (Houwen, Visser, van der Putten, \& Vlaskamp, 2016; Visser et al., 2017). For example, in a study on child attachment (Vandesande et al., 2019a), 
RUNNING HEAD: Methodological challenges and future directions

parents were asked to indicate if a child seeks physical proximity when he is scared (Secure Base Safe Haven Observation List; De Schipper, Schuengel, Stolk, \& Janssen, 2004). To achieve a high score on this item, children need to show highly physical and purposeful behaviour in response to a stimulus (i.e., fear) they might not experience. Another example can be found in the study of van der Putten, Dijkstra, Huls and Visser (2017) in which two commonly used instruments for the assessment of temperament were applied among children with PIMD. Results showed that over $20 \%$ of the items contained motor behaviour which biased the validity of the instrument. Therefore, researchers are challenged to reflect on the concrete behavioural operationalisations (based on typical development and functioning) in relation to the underlying latent variables of the items and the instrument as a whole. An associated issue is that instruments aimed at the general population are often insufficient to capture subtlety in behaviour, functioning and development, certainly at the lowest scores (van der Putten et al., 2017; Vandesande et al., 2019a), which impedes meaningful differentiation within the group of persons with PIMD.

In conclusion, the research field could greatly benefit from the development and validation of research-oriented instruments specifically tailored to the target group. In the area of communication for example, some instruments have been specifically developed for the PIMD-group, including some with established psychometric properties; see Chadwick, Buell, and Goldbart's (2019) survey. However, this process is inevitably challenged by the heterogeneity of the PIMD-group (cf. section 1) and the challenges in participant recruitment (cf. section 2).

With regard to specific types of measurement, the use of self-report is not considered a viable option due to the limited cognitive, communicative and reflective capabilities of persons with PIMD (Ware, 2004). Therefore, two commonly used methods are proxy reports and behavioural observation. By using proxy reports, researchers incorporate the expertise of those 
RUNNING HEAD: Methodological challenges and future directions

who have the most experience with and the most intimate knowledge of the person with PIMD (Petry, Maes, \& Vlaskamp, 2009; Kruithof et al., 2020). However, using proxy reports also challenges the researcher to reflect on the degree to which the report really approximates the participant's perspective. This might be more challenging in evaluations of rather subjective themes such as emotional experiences and personal preferences, than for more objective issues such as cognitive, communicative and motor behaviour (Vos, De Cock, Petry, Van Den Noortgate, \& Maes, 2010). As is the case in all research, whenever proxies are involved, researchers should be cautious of social desirability bias and seek to validate proxy reports through behavioural observations (see below and Goldbart \& Marshall, 2011).

A second commonly used method in studying persons with PIMD, is direct behavioural observation (e.g. Hostyn, Neerinckx, \& Maes, 2011; Lambrechts, Van Den Noortgate, Eeman, \& Maes, 2010; Munde, Vlaskamp, Maes, \& Ruijssenaars, 2014; Neerinckx et al., 2014; Nijs, Penne, Vlaskamp, \& Maes, 2015; Van keer et al., 2019; Vandesande et al., 2019a; Vos, De Cock, Petry, Van Den Noortgate, \& Maes, 2013a; 2013b). This method allows researchers to attend closely to the person's actual behaviour in real life, taking into account the context of the observed behaviour, without solely depending on proxies' interpretation. In addition, the use of video recordings allows researchers to analyse their data afterwards (as opposed to in situ), giving rise to more complex coding procedures, recoding opportunities (cf. intra-observer reliability) and inter-observer discussion.

However, the validity and reliability of behavioural observations in this target group is often challenged. A lot of variables related to the context (e.g. location, time, observer) and to the person (e.g. health condition, positioning) have to be taken into account. The balance must be found between on the one hand, the search for standardization in order to ensure procedural fidelity and on the other hand, adaptation to the individual constraints of each participant. 
RUNNING HEAD: Methodological challenges and future directions

Conducting a pilot study can be a wise methodological precaution (e.g. Dind, 2020), to evaluate if the procedure succeeds in achieving that balance.

Further, behavioural coding may be difficult because of the often idiosyncratic nature of behaviours of persons with PIMD (Hostyn \& Maes, 2009). With regard to validity, researchers are confronted with the tension between a more deductive approach (e.g., using an existing or adapted observational scheme) and a more inductive approach (e.g., developing a new scheme based on observations). Combining both approaches, namely adapting existing schemes based on observations, might also be a valuable strategy (Dhondt, Van keer, Nijs, van der Putten, \& Maes, submitted; Nijs, Vlaskamp, \& Maes, 2015; Van keer et al., 2019). However, the chosen method should rely heavily on the specific aim of the study. With regard to reliability, observational studies in this target group often report a lower level of inter-rater reliability compared to observational studies in other target groups. Nicholas, Geers, and Rollins (1999) argued that the ambiguity reflected in poor coder agreement for less skilled communicators may represent the extent to which these persons are understood. Even so, many actions can be taken to obtain the highest possible inter-rater agreement. Researchers can develop an extensive scoring manual and provide coders with intensive training (e.g. Van keer et al., 2019; Vandesande et al., 2019b). The use of communication or personal profiles implies that coders use the experiential knowledge of parents or direct support staff, who are questioned about the typical communicative behaviours of the person with PIMD (Petry \& Maes, 2006). Furthermore, accompanying scoring protocols with detailed descriptive comments to stimulate discussion can be helpful by including this qualitative information in data analysis or by using it in a consensus rating procedure (i.e., inter-discussion-reliability), which enables the researcher to verify whether raters agree in their allocated scores but also in the observations made (Vandesande et al., submitted). 
RUNNING HEAD: Methodological challenges and future directions

A promising practice could be to involve parents and/or professionals in coding and interpretation, since reliability is shown to be dependent on the observer's specific individual knowledge about the person with PIMD (Vlaskamp \& Cuppen-Fonteine, 2007). Depending on the study's aim, familiar caregivers can be involved in different degrees of intensity, from solely providing information for building a communication or personal profile, to identifying typical behavioural expressions of the variable of interest in the dataset (i.e., through video fragments or photographs), to even coding the full data set. Many forms of cooperation between the researcher and the familiar informant are possible, for example by combining the input from a coder with general knowledge on persons with PIMD and the input of a coder with specific knowledge on the participant.

Recently, researchers have started to use physiological measures to avoid the difficulties in interpreting behavioural observations, or to validate these behavioural observations. Vandesande et al. (2019b) measured skin conductance with the sensor sock (Sterkenburg et al., 2017), to corroborate the behavioural observations of attachment behaviour. Vos et al. (2013a; 2013b) measured breathing and heart rate variables with the non-invasive ambulatory Dreamer ${ }^{\circledR}$ technology (Medatec) to evaluate emotions of persons with PIMD when confronted with positive and negative stimuli. The startle reflex modulation technique (SRM), measuring eye blink amplitude, can be used to infer broad positive or negative emotional responses. Lyons, Walla and Arthur-Kelly (2013) suggested its use for better understanding the choices and preferences of persons with PIMD. These methods have an added value to the behavioural observations, especially in those cases when the idiosyncratic behaviour is difficult to interpret by the researcher. Of course, here also, the specific characteristics of this target group create challenges in the use and interpretation of physiological measures, for example because of the presence of epilepsy, atypical eye movements, disturbances in sweat production, interference of specific medications etc. 
RUNNING HEAD: Methodological challenges and future directions

An additional challenge that often confronts researchers is the fluctuating levels of alertness and attention in persons with PIMD during the course of the day and/or over a longer period of time (Munde et al., 2014). In the case of behavioural observations, incorporating repeated measures (Dind, 2018) and/or applying continuous coding (Nijs et al., 2015) seem to be the most consistent means of dealing with this challenge. When specific behaviours are recorded within small time segments, the specific coding strategy such as interval coding (Hostyn, Neerinckx, \& Maes, 2011; Munde et al., 2014) or event coding (Van keer et al., 2019) can vary depending on the specified research question. However, when applying a molar (i.e., macro-level) approach in which global ratings are applied to an entire observation, major fluctuations in target behaviour can impede reliable coding. A possible solution is to subdivide longer fragments into smaller time sections to increase reliability (Van keer et al., 2017).

Using experience sampling methods (ESM) may also provide insights into personspecific mechanisms. ESM is an intensive data collection technique in which observations are made on multiple occasions per day, and usually for several days (Larson \& Csikszentmihalyi, 2014). By repeatedly measuring behaviours, at the time that these occur, a more comprehensive and valid insight is possible into the individual differences, fluctuations and changes within the individual. In addition, one can examine associations with contextual variables. New measurement techniques such as a smartphone app may facilitate this type of intensive data collection by easing the various situational data collection challenges often faced in live observations.

Primarily due to transportation difficulties, busy schedules, and the health status of persons with PIMD generally, research with this target group takes place in the home or in another daily life context of the child or adult (e.g. school, care facility, day service). This provides a naturalistic and representative context for their behaviour, which certainly improves 
RUNNING HEAD: Methodological challenges and future directions

a study's ecological validity. However, these environments are more easily associated with disruptive variables, such as noise and interruptions by staff.

It is clear that several considerations have to be made when deciding which research instrument or data collection procedure renders the most reliable and valid data for a specific study involving persons with PIMD. It might be worthwhile to combine different complementary assessment methods (e.g. validating behavioral data with physiological measures; Munde, Vlaskamp, Vos, Maes, \& Ruijssenaars, 2012, mixing findings from qualitative and quantitative research; Heyvaert, Maes, \& Onghena, 2011) which can give way to more complete, concrete, and nuanced answers to the inevitably complex research questions regarding persons with PIMD.

\section{Data analysis}

The previously described challenges with regard to demarcation of the target group, recruitment of participants, and data collection and instruments lead to specific challenges in data analysis. The target group of persons with PIMD is very heterogeneous. Researchers are aware of the potential influence of various disabilities on the topic of research, such as the influence of visual and motor limitations (Dhondt et al., 2019; Houwen et al., 2016) or of genetic syndromes (Moss et al., 2016; Pearson, Wilde, Heald, Royston, \& Oliver, 2019) on social and communicative behaviour. It is, however, not always possible to take this variation into account in the analysis. Making sub-groups, comparing groups, or including specific disabilities as an influencing factor in quantitative analyses is often impossible because of the small sample sizes. Research questions on a group level may be difficult to answer because of the heterogeneity on an individual level (Bossink et al., 2017).

Small sample sizes make it impossible to use parametric analyses because the necessary assumptions are often not met. Moreover, the heterogeneity in the sample may lead to a skewed 
RUNNING HEAD: Methodological challenges and future directions

distribution. Consequently, researchers are forced to use non-parametric analyses. Compared to parametric analyses, non-parametric analyses have less power, thereby lowering the chance of detecting an effect. Hence, PIMD research is often descriptive and interventions for persons with PIMD are not always supported by evidence (Goldbart \& Caton, 2010; Vlaskamp \& Nakken, 2008).

In recent years, researchers have applied single case experimental designs to overcome the challenges of the heterogeneity and the small sample sizes (e.g. Lancioni et al., 2007, 2010; Nijs, Vlaskamp, \& Maes, 2018). Some new or rediscovered techniques are applied to analyse multiple behavioural codings, such as time window sequential analysis (Munde et al., 2014), multivariate, binary time series data (Van keer et al., 2019) or clusterwise hierarchical classes analysis (HICLAS) (Wilderjans, Lambrechts, Maes, \& Ceulemans, 2014). Techniques such as structural equation modelling to analyse longitudinal data look very promising in order to find a balance between analyses on group or individual levels. To overcome some of the abovementioned difficulties, researchers may also apply mixed method approaches (Onghena, Maes, \& Heyvaert, 2018).

In doing qualitative research by means of interviews or observations in the group of persons with PIMD and their families, the main issue refers to what Lincoln and Guba (1985) describe as the transferability and credibility (which could be seen as the parallels to reliability and validity) of qualitative data analysis. Possible ways of increasing the transferability and credibility, are member checks, consensus of coding procedures, using thick descriptions, justifying interpretations by concrete observations or statements, and combining data from different sources (Balandin \& Goldbart, 2011; Hostyn \& Maes, 2013). Both Griffiths and Smith (2016) and Martin, Goldbart and Andrews (2019), for example, have applied Classic Grounded Theory to explore the meaning-making process between persons with PIMD and their communication partner by combining analysis of observations and interviews. Another 
RUNNING HEAD: Methodological challenges and future directions

qualitative approach used in research on persons with PIMD is Interpretative Phenomenological Analysis. IPA has been applied to video-data to give meaning to the interactions during music therapy (Lee \& McFerran, 2015) or to analyse interview data with carers on conceptualizing bereavement in persons with PIMD (Young, Hogg, \& Gerrard, 2017) and their beliefs about development (Rees, 2019). These approaches often do more justice to the heterogeneity of the target population, notwithstanding the fact that the results of these studies may not always allow, or even intend, to draw general conclusions for the population.

Another challenge researchers encounter during data analysis is the difficulty in finding an appropriate control group. The use of a control group in research designs is common practice to corroborate the findings and to demonstrate effectiveness of interventions. Participants can be matched based, for example, on a specific disability, age, or developmental level. However, due to the complexity of the disabilities and the heterogeneity in the target PIMD group, it often remains unclear which characteristics are most relevant when composing a control group for the specific research question. Therefore (multiple) baseline measures, ipsative comparisons, or alternative designs, such as stepped wedge design, may be more useful in this target group (e.g. Lancioni et al., 2007, 2010, Poppes et al., 2016).

\section{Ethics/Including the 'voice' of persons with PIMD}

Throughout the years, conducting inclusive research has gained importance in order to make sure that the voice of persons with ID and their families is heard throughout the whole research process (Embregts, Taminiau, Heerkens, Schippers, \& Van Hove, 2018; Frankena, Naaldenberg, Cardol, Linehan, \& van Schrojenstein Lantman-de Valk, 2015). Integrating this approach in research on persons with PIMD is a challenge (Mietola, Mietinnen, \& Vehmas, 2017). 
RUNNING HEAD: Methodological challenges and future directions

A first issue is obtaining informed consent. Persons with PIMD are limited in their ability to fully provide informed consent. Many countries have legislation or guidance on this issue, which may require researchers to ask primary caregivers or other agreed decision-makers to provide informed consent (i.e., 'proxy consent') on behalf of the participant. Some parents or decision-makers seem to be anxious, however, about their right to do this. Although the ethical considerations associated with proxy consent strongly urge researchers to ensure a clear consent procedure and close collaboration with a specialised ethical committee, "what is immoral is neglecting or avoiding to do research with this population simply because it is impossible to obtain consent in the usual way. Such an attitude denies this group the possibility of any improvement in care that might result from our work." (Morse, 2000, p. 542). Therefore, Simmons and Watson (2015) argue that instead of positioning persons with PIMD as incompetent and lacking 'voice' or positioning researchers as lacking the appropriate tools to gain access to such voice, we can focus on voice not as singular and literal, but as something that is enacted or comes into being through relationships. As a parent stated, he always asked himself whether his child would be fine with participating in a particular research project and providing the researchers with this intimate information, before he gave consent. In addition, it remains important throughout the whole data collection phase to monitor the participants' willingness to participate in research (Mietola et al., 2017; Nijs, Vlaskamp, \& Maes, 2018). This can be operationalised by means of an individualised assent protocol which allows the researcher to appraise, on a regular basis, whether the person with PIMD is still willing to take part or is showing behaviour that suggests he/she wants to withdraw. It can be included in the assent protocol, for example, that the behavioral indicators of the person with PIMD can overrule the proxy-consent. Another idea that might be adopted is to break the consent process down in different stages (e.g. it may not be possible for a person with PIMD to give consent to the entire research project, but he/she can show whether he/she agrees to being video-taped). 
RUNNING HEAD: Methodological challenges and future directions

Further, Gjermestad and Skarsaune (submitted) conducted a review in which they identified three ways to include the voice of persons with PIMD within the research process: a. ethnographic approaches (e.g. long periods of observations), b. creative approaches (e.g. photo voice projects, theatre) and c. involving significant others and proxies. Ethnographic approaches have already been applied in research on communication (Forster \& Iacono, 2014; Griffiths \& Smith, 2016) and quality of life (Lyons, 2005) in persons with PIMD. These researchers participated for a longer period of time in the daily life situation of a small number of persons with PIMD, observing their behaviour and providing meaning to their behaviour. This often led to the adaptation of existing theoretical frameworks or to the development of new ones. Gjermestad and Skarsaune (submitted) stress that the voice of persons with PIMD is something dialogical, emphasizing the intersubjective and bodily knowledge between persons who know each other well. In that way, the voice of persons with PIMD can also be effectively included by 'listening' carefully to their emotional utterances, gestures and sounds. Another technique with potential, is 'shadowing' (Johnson, 2014; McDonald, 2005). This implies taking the time to be together with a person and to observe and take part in all daily activities of the person. In implementing this method, often a phenomenological approach is used, in which the researcher includes bodily experiences and is reflexive upon his/her own experiences (Gill, 2011; Van der Weelde \& Bredewold, in preparation).

The third option suggested by Gjermestad and Skarsaune (submitted), involving significant others and proxies, can be accomplished by acknowledging them as experts by experience (see also section 3 on data collection). A recent literature review describes the unique and experiential knowledge of parents on their child with PIMD. The authors conclude that parents are experts in the knowledge of their child's communication, well-being and pain. They can also be advocates by using their knowledge opposed to the objectivism of medical approaches and by translating their knowledge so it is more accepted within health care and 
RUNNING HEAD: Methodological challenges and future directions

medicine. This knowledge, gathered through intensive interactions, is transferable and may help others acquiring a deeper understanding of the person with PIMD (Kruithof, Willems, van Etten-Jamaludin, \& Olsman, 2020). Also, for research to be truly inclusive, the research question that is explored has to be owned or have relevance to those involved and they should have the possibility to really influence (part of) the research process (Gjermestad \& Skarsaune, submitted). To illustrate, in 2018, the SIRG PIMD discussed the motivation of parents concerning participation in research. Two parents were interviewed and explained that gaining more knowledge on the specific syndromes of their child with PIMD was their main motivation to participate, but becoming part of a community of families participating in research was also mentioned. Parents would participate not only for the benefit of their own child, but also for the benefit of the children with similar needs in other families. There were, however, some issues parents took into consideration before deciding on whether or not to participate. First, the topic of the research must fit in with the daily problems family struggle with; it must therefore be directly relevant to their own daily life. Second, the engagement that is asked for from participants must be in compliance with the family's daily routines. In that respect, researchers must also be flexible in their research protocols to ensure this compliance. Third, parents expect the researcher to be sensitive to and considerate of the situation of the family. This calls for sensitivity and rapport on the part of the researchers, especially when visiting families at home. Fourth, parents expect clear communication from the researcher with regard to what is expected from the research participants. In addition, parents also appreciate being able to give feedback to the researcher about his/her research (that the research is not yet "set in stone"). Recently, in the Netherlands, a research agenda was developed from the perspective of parents to ensure that the research topics that will be addressed in future research actually meet their needs (EMB Nederland, Onderzoeksagenda EMB). In several projects, the involvement of parents in research is even more substantial by including them as a member of the scientific research team 
RUNNING HEAD: Methodological challenges and future directions

(e.g., to observe and analyse video recordings of their child with PIMD, cf. section 3). Parents may also be involved in concept mapping procedures (e.g. Hanzen, van Nispen, van der Putten, \& Waninge, 2017; Munde, Vlaskamp, Ruijssenaars, \& Nakken, 2009). Using the 'involvement matrix’ (Kenniscentrum Revalidatiegeneeskunde Utrecht, 2017), parents and researchers can discuss the roles of parents and other relatives throughout the different stages of the research.

\section{Theoretical models}

Since research on PIMD is a relatively young field, developed over the past four to five decades, there is still a paucity of specific theoretical frameworks available, that could lay the foundations for the development of assessment instruments and intervention tools. Therefore, researchers in this field are often dependent upon general theories which are conceptualised with typically developing persons in mind. However, it is not certain that these theories always fully apply, due to the complex interplay between cognitive, motor and/or sensory impairments of persons with PIMD. For example, it is still questionable if the developmental trajectories of persons with PIMD on various domains (e.g., social-emotional, cognitive, communicative) are similar, though delayed, when compared to typically developing persons and/or fundamentally different or disharmonic (e.g., Dhondt et al., 2019; van der Putten, Vlaskamp, Reynders, \& Nakken, 2005; Vandesande, Van keer, Dhondt, \& Maes, submitted; Visser, Vlaskamp, Emde, Ruiter, \& Timmerman, 2017).

Over the past years, researchers seeking to understand the experiences and capabilities of persons with PIMD have addressed this issue in two ways. On the one hand, they have applied general theories to this particular group (e.g., ecological self-awareness, Dind, 2018; affect attunement, Forster \& Iacono, 2014; attentional processes, Neerinckx, Vos, Van den Noortgate, \& Maes, 2014; attachment theory, Vandesande, Bosmans, Schuengel, \& Maes, 2019a; ecocultural theory, Van keer, Seghers, Van Leeuwen, \& Maes, 2020). In this approach, 
RUNNING HEAD: Methodological challenges and future directions

the core concepts of the theory are considered to be equally important for persons with PIMD, but often adaptation is needed to provide more specific behavioural indicators for those concepts. On the other hand, specific theories have been developed to describe the situation of persons with PIMD (e.g., Levensloop in perspectief, Vlaskamp, Poppes, \& Zijlstra, 2005; Explanatory model of the interaction between persons with PIMD and their partners, Hostyn \& Maes, 2009). The further development of theory, in which these two approaches are balanced, is crucial to improve quality of life and support to persons with PIMD (Arthur-Kelly, Foreman, Maes, Colyvas, \& Lyons, 2018). Future research on PIMD could, furthermore, benefit from moving beyond mere descriptive research to reveal explanatory mechanisms in order to design targeted interventions (e.g. Chard, Roulin, \& Bouvard, 2014, Vandesande et al., 2019). The evolutions with regard to data analyses (cf. section 4) may provide researchers with tools to conduct sound research with good evidential value to address this need.

\section{Conclusion}

Looking back on the past decades of PIMD research, researchers have come across specific challenges that are driven by the specific characteristics of this target group, which is heterogeneous, small in numbers, severe with regard to the disability and vulnerable. Researchers in this field have struggled over the years with participant demarcation, recruiting participants, finding valid and reliable instruments, analysing data, including the voice of persons with PIMD and their parents and contributing to the development of new theories. We can certainly expect the same issues to continue to challenge researchers within this field. However, researchers have also found a great number of creative and inventive ways to address these challenges. Reflecting on these solutions and looking forward to pathways for the future, a new wave of PIMD research seems to be arriving in favour of a comprehensive understanding of persons with PIMD and their support systems. We hope that the current contribution and the 
RUNNING HEAD: Methodological challenges and future directions

activities of the SIRG-PIMD can fuel further discussion, stimulate creative research techniques and encourage further exchange of ideas. We trust this paper has shed light on where we have been, and where we should be heading. 
RUNNING HEAD: Methodological challenges and future directions

\section{References}

American Psychiatric Association. (2013). Diagnostic and statistical manual of mental disorders (5th ed.). Washington, DC: Author.

Arthur-Kelly, M., Foreman, P., Maes, B., Colyvas, K., \& Lyons, G. (2018). Observational data on sociocommunicative phenomena in classrooms supporting students with profound intellectual and multiple disability (PIMD): advancing theory development on learning and engagement through data analysis. Advances in Neurodevelopmental Disorders, 2(1), 25-37. doi: 10.1007/s41252017-0045-1

Axelsson, A.K. \& Wilder J. (2014). Frequency of occurrence and child presence in family activities: a comparative study of children with profound intellectual and multiple disabilities and children with typical development. International Journal of Developmental Disabilities, 60(1), 13-25. doi:10.1179/2047387712Y.0000000008

Balandin, S., \& Goldbart, J. (2011). Qualitative research and AAC: Strong methods and new topics. Augmentative and Alternative Communication, 27,227-228. doi: 10.3109/07434618.2011.630409

Bellamy, G., Croot, L., Bush, A., Berry, H., \& Smith, A. (2010). A study to define: profound and multiple learning disabilities (PMLD). Journal of Intellectual Disabilities, 14(3), 221-235. doi:10.1177/1744629510386290

Berk, L.E. (2010). History, theory and research strategies. In Mosher, J. (Ed.), Development through the lifespan, Fifth edition (pp. 3-43). Boston, MA: Pearson International Edition.

EMB Nederland. Over EMB Nederland. [About PIMD The Netherlands]. Retrieved from https://embnederland.nl/over-emb-nederland/

EMB Nederland. Onderzoeksagenda EMB. [Research agenda PIMD]. Retrieved from https://embnederland.nl/over-emb-nederland/wat-we-doen/projecten/

Bossink, L.W., van der Putten, A.A., Waninge, A., \& Vlaskamp, C. (2017). A power-assisted exercise intervention in people with profound intellectual and multiple disabilities living in a residential facility: a pilot randomised controlled trial. Clinical rehabilitation, 31(9), 1168-1178. doi:10.1177/0269215516687347

Chadwick, D., Buell, S., \& Goldbart, J. (2019). Approaches to communication assessment with children and adults with profound and multiple learning disability. Journal of Applied Research in Intellectual Disabilities. 32(2), 336-358. doi:10.1111/jar.12530

Chard, M., Roulin, J. L., \& Bouvard, M. (2014). Visual habituation paradigm with adults with profound intellectual and multiple disabilities: a new way for cognitive assessment?. Journal of Applied Research in Intellectual Disabilities, 27(5), 481-488. doi: 10.1111/jar.12079

Cooper, S.A., Smiley, E., Finlayson, J., Jackson, A., Allan, L., Williamson, A., ... \& Morrison, J. (2007). The prevalence, incidence, and factors predictive of mental ill-health in adults with profound 
RUNNING HEAD: Methodological challenges and future directions

intellectual disabilities. Journal of Applied Research in Intellectual Disabilities, 20(6), 493-501. doi:10.1111/j.1468-3148.2007.00401.x

De Schipper, J.C. \& Schuengel, C., Stolk, J., \& Janssen, C.G.C. (2004). Veilige basis veilige haven observatielijst. Gehechtheidsgedrag van het kind. Versie: groepsopvang j/m. [Safe base safe haven observation list. Attachment behavior of the child. Version: group care b/g]. Unpublished manuscript, Vrije Universiteit Amsterdam, Faculteit Psychologie en Pedagogiek.

Dhondt, A., Van keer, I., Nijs, S., van der Putten, A.A.J., \& Maes, B. (submitted). In search of a novel way to analyze early communicative behaviours in young children with significant cognitive and motor developmental delays.

Dhondt, A., Van keer, I., van der Putten, A.A.J. \& Maes, B. (2019). Communicative abilities in young children with a significant cognitive and motor developmental delay. Journal of Applied Research in Intellectual Disabilities. Advance online publication. doi: 10.1111/jar.12695

Dind, J. (2018). Les manifestations de la conscience de soi chez l'enfant polyhandicapé: Edification d'un outil d'observation au service des professionnels. [Demonstrations of self-awareness in the multi-handicapped child: Edification of an observation tool at the service of professionals]. (Doctoral dissertation). Retrieved from http://doc.rero.ch/record/306941

Dind, J. (2020). La conscience de soi au prisme du polyhandicap. Mieux la connaître, l'observer et stimuler son développement. Guibiasco, Suisse: Edizioni Fondazione ARES.

Dunst, C. J. (1980). A clinical and educational manual for use with the Uzgiris and Hunt Scales of Infant Psychological Development. Baltimore: University Park Press.

Embregts, P.J.C.M., Taminiau, E.F., Heerkens, L., Schippers, A.P., \& Van Hove, G. (2018). Collaboration in inclusive research: competencies considered important for people with and without intellectual disabilities. Journal of Policy and Practice in Intellectual Disabilities, 15, 193-201. doi:10.1111/jppi.12248

Evenhuis, H.M., Theunissen, M., Denkers, I., Verschuure, H., \& Kemme, H. (2001). Prevalence of visual and hearing impairment in Dutch institutionalised population with intellectual disability. Journal of Intellectual Disability Research, 45, 457-464. doi:10.1046/j.1365-2788.2001.00350.x

Forster, S., \& Iacono, T. (2014). The nature of affect attunement used by disability support workers interacting with adults with profound intellectual and multiple disabilities. Journal of Intellectual Disability Research, 58(12), 1105-1120. doi:10.111/jjr.12103

Frankena, T.K., Naaldenberg, J., Cardol, M., Linehan, C., \& van Schrojenstein Lantman-de Valk, H. (2015). Active involvement of people with intellectual disabilities in health research - A structured literature review. Research in Developmental Disabilities, 45-46, 271-283. doi:10.1016/j.ridd.2015.08.004

Gill, R. (2011). The shadow in organizational ethnography: moving beyond shadowing to spect-acting. Qualitative Research in Organizations and Management: An International Journal, 6(2), 115133. doi: $10.1108 / 17465641111159116$ 
RUNNING HEAD: Methodological challenges and future directions

Gjermestad, A. \& Skarsaune, S. (submitted). Advancing inclusive research with people with profound and multiple learning disabilities through a sensory-dialogical approach. Qualitative Social Work.

Goldbart, J., \& Caton, S. (2010). Communication and people with the most complex needs: What works and why this is essential. London: Mencap.

Goldbart, J., \& Marshall, J. (2011). Listening to proxies for children with speech, language and communication needs. In S. Roulstone and S. McLeod (Eds.), Listening to children and young people with speech, language and communication needs. Guildford: J\&R Press.

Gorter, J. W., Ketelaar, M., Rosenbaum, P., Helders, P. J., \& Palisano, R. (2009). Use of the GMFCS in infants with CP: the need for reclassification at age 2 years or older. Developmental Medicine \& Child Neurology, 51(1), 46-52. doi:10.1111/j.1469-8749.2008.03117.x

Griffiths, C. \& Smith, M. (2016). Attuning: A communication process between people with severe and profound intellectual disability and their interaction partners. Journal of Intellectual Disabilities, 29(2), 124-138. doi:10.1111/jar.12162

Hanzen, G., van Nispen, R. M., van der Putten, A. A., \& Waninge, A. (2017). Participation of adults with visual and severe or profound intellectual disabilities: Definition and operationalization. Research in developmental disabilities, 61, 95-107. doi:10.1016/j.ridd.2016.12.017

Hatton, C., Glover, G., Emerson, E., \& Brown, I. (2016). People with learning disabilities in England 2015: Main report. London: Public Health England.

Hogg, J., Juhlberg, K., \& Lambe, L. (2007). Policy, service pathways and mortality: a 10-year longitudinal study of people with profound intellectual and multiple disabilities. Journal of Intellectual Disability Research, 51(5), 366-376. doi:10.1111/j.1365-2788.2006.00884.x

Hostyn, I., \& Maes, B. (2009). Interaction between persons with profound intellectual and multiple disabilities and their partners: A literature review. Journal of Intellectual \& Developmental Disability, 34(4), 296-312. doi:10.3109/13668250903285648

Hostyn, I., \& Maes, B. (2013). Interaction with a person with profound intellectual and multiple disabilities: A case study in dialogue with an experienced staff member. Journal of Intellectual and Developmental Disability, 38(3), 189-204. doi:10.3109/13668250.2013.798400

Hostyn, I., Daelman, M., Janssen, M.J., \& Maes, B. (2010). Describing dialogue between persons with profound intellectual and multiple disabilities and direct support staff using the scale for dialogical meaning making. Journal of Intellectual Disability Research, 54(8), 679-690. doi:10.1111/j.1365-2788.2010.01292.x

Hostyn, I., Neerinckx, H., \& Maes, B. (2011). Attentional processes in interactions between people with profound intellectual and multiple disabilities and direct support staff. Research in Developmental Disabilities, 32(2), 491-503. doi:10.1016/j.ridd.2010.12.034

Hostyn, I., Petry, K., Lambrechts, G., \& Maes, B. (2011). Evaluating the quality of the interaction between persons with profound intellectual and multiple disabilities and direct support staff: A preliminary application of three observation scales from parent-infant research. Journal of 
RUNNING HEAD: Methodological challenges and future directions

Applied Research in Intellectual Disabilities, 24(5), 407-420. doi:10.1111/j.14683148.2010.00618.x

Houwen, S., Visser, L., van der Putten, A., \& Vlaskamp, C. (2016). The interrelationships between motor, cognitive, and language development in children with and without intellectual and developmental disabilities. Research in Developmental Disabilities, 53, 19-31. doi:10.1016/j.ridd.2016.01.012

Johnson, B. (2014). Ethical issues in shadowing research. Qualitative Research in Organizations and Mangement: An International Journal, 9(1), 21-40. doi: 10.1108/QROM-09-2012-1099

Kenniscentrum Revalidatiegeneeskunde Utrecht (2017). Involvement matrix. Retrieved from https://www.kcrutrecht.nl/involvement-matrix/

Kiernan, C., \& Jones, M. (1977). Behaviour Assessment Battery. Windsor: NFER.

Kirkman, B.L., \& Chen, G. (2011). Maximizing your data or data slicing? Recommendations for managing multiple submissions from the same dataset. Management and Organization Review, 7(3), 433-446. doi:10.1111/j.1740-8784.2011.00228.x

Kooiker, M. J. G., Pel, J. J. M., Verbunt, H. J. M., de Wit, G. C., van Genderen, M. M., \& van der Steen, J. (2016). Quantification of visual function assessment using remote eye tracking in children: validity and applicability. Acta Ophthalmologica, 94(6), 599-608. doi:10.1111/aos.13038

Kraijer, D., \& Plas, J. (2007). Handboek psychodiagnostiek en beperkte begaafdheid. [Manual Psychodiagnostics and intellectual disability]. Amsterdam, Harcourt Book Publishers.

Kruithof, K., Willems, D., van Etten-Jamaludin, F., \& Olsman, E. (2020). Parents' knowledge of their child with profound intellectual and multiple disabilities: An interpretative synthesis. Journal of Applied Research in Intellectual Disabilities. doi: 10.1111/jar.12740

Lambrechts, G., Van Den Noortgate, W., Eeman, L., \& Maes, B. (2010). Staff reactions to challenging behaviour: An observation study. Research in Developmental Disabilities, 31, 525-535. doi:10.1016/j.ridd.2009.12.004

Lancioni, G. E., Bellini, D., Oliva, D., Singh, N. N., O’Reilly, M. F., \& Sigafoos, J. (2010). Camerabased microswitch technology for eyelid and mouth responses of persons with profound multiple disabilities: Two case studies. Research in Developmental Disabilities, 31(6), 1509-1514. doi:10.1016/j.ridd.2010.06.006

Lancioni, G. E., O ‘Reilly, M.,F., Singh, N. N., Sigafoos, J., Oliva, D., Campodonico, F., \& Groeneweg, J. (2007c). Helping three persons with multiple disabilities acquire independent dressing through assistive technology. Journal of Visual Impairment \& Blindness, 101(12), 768773. doi:10.1177\%2F0145482X0710101207

Larson, R., \& Csikszentmihalyi, M. (2014). The experience sampling method. In Csikszentmihalyi, M. (Ed.), Flow and the foundations of positive psychology (pp. 21-34). Springer, Dordrecht.

Lebeer, J., Nijland, M., Grácio, L., \& Schraepen, B. (2017). Enabling activity and participation: Supporting young people with complex and intense support needs. Varna, Bulgaria: Halix Press. 
RUNNING HEAD: Methodological challenges and future directions

Lee, J., \& McFerran, K. S. (2015). Applying interpretative phenomenological analysis to video data in music therapy. Qualitative Research in Psychology, 12(4), 367-381. doi:10.1080/14780887.2014.960985

Lincoln, Y., \& Guba, E. (1985). Naturalistic inquiry. Thousand Oaks, CA: Sage Publications.

Luijkx, J., van der Putten, A. A. J., \& Vlaskamp, C. (2017). Time use of parents raising children with severe or profound intellectual and multiple disabilities. Child: Care, Health and Development, 43(4), 518-526. doi: 10.1111/cch.12446

Luijkx, J., van der Putten, A. A., \& Vlaskamp, C. (2016). "I love my sister, but sometimes I don't": A qualitative study into the experiences of siblings of a child with profound intellectual and multiple disabilities. Journal of Intellectual \& Developmental Disability, 41(4), 279-288. doi:10.3109/13668250.2016.1224333

Lyons, G. (2005). The Life Satisfaction Matrix: an instrument and procedure for assessing the subjective quality of life of individuals with profound multiple disabilities. Journal of Intellectual Disability Research, 49, 766-769. doi:10.1111/j.1365-2788.2005.00748.x

Lyons, G., Walla, P., \& Arthur-Kelly, M. (2013). Towards improved ways of knowing children with profound multiple disabilities: Introducing startle reflex modulation, Developmental Neurorehabilitation, 16, 340-344. doi: 10.3109/17518423.2012.737039

Martin, A.M., Goldbart, J., \& Andrews, T. (2019). Classic Grounded Theory (CGT) as an approach to research involving people with severe/profound intellectual disability. Presentation at the World Congress of IASSIDD, Glasgow, p.820.

McDonald, S. (2005). Studying actions in context: a qualitative shadowing method for organizational research. Qualitative Research, 5(4), 455-473. doi: 10.1177/1468794105056923

Mietola, R., Miettinen, S., \& Vehmas, S. (2017). Voiceless subjects? Research ethics and persons with profound intellectual disabilities. International Journal of Social Research Methodology, 20(3), 263-274.

Morse, J. M. (2000). Researching illness and injury: Methodological considerations. Qualitative Health Research, 10(4), 538-546. doi:10.1177/104973200129118624

Moss, J., Nelson, L., Powis, L., Waite, J., Richards, C., \& Oliver, C. (2016). A comparative study of sociability in Angelman, Cornelia de Lange, Fragile X, Down and Rubinstein Taybi syndromes and Autism Spectrum Disorder. American Journal on Intellectual and Developmental Disabilities, 121, 465-486. doi:10.1352/1944-7558-121.6.465

Multiplus. Lopend en afgerond onderzoek. [Current and completed research]. Retrieved from https://www.multiplus.be/onderzoek

Munde, V., Vlaskamp, C., Ruijssenaars, W., \& Nakken, H. (2009). Experts discussing "alertness in individuals with PIMD”: A concept mapping procedure. Journal of Developmental and Physical Disabilities, 21(4), 263-277. doi:10.1007/s10882-009-9141-0 
RUNNING HEAD: Methodological challenges and future directions

Munde, V.S., Vlaskamp, C., Maes, B., \& Ruijssenaars, A. J. J. M. (2014). Catch the wave! Time-window sequential analysis of alertness stimulation in individuals with profound intellectual and multiple disabilities. Child: Care, Health \& Development, 40(1), 95-105. doi:10.1111/j.13652214.2012.01415.x

Nakken, H., \& Vlaskamp, C. (2002). Joining forces: supporting individuals with profound multiple learning disabilities. Tizard Learning Disability Review, 7, 10-15. doi:10.1108/13595474200200023

Nakken, H., \& Vlaskamp, C. (2007). A need for a taxonomy for profound intellectual and multiple disabilities. Journal of Policy and Practice in intellectual Disabilities, 4(2), 83-87. doi:10.1108/13595474200200023

Neerinckx, H., Vos, P., Van Den Noortgate, W., \& Maes, B. (2014). Temporal analysis of attentional processes in spontaneous interactions between people with profound intellectual and multiple disabilities and their support workers. Journal of Intellectual Disability Research, 58(8), 721-733. doi: $10.1111 /$ jir

Nicholas, J. G., Geers, A. E., \& Rollins, P. R. (1999). Inter-rater reliability as a reflection of ambiguity in the communication of deaf and normally-hearing children. Journal of Communication Disorders, 32(2), 121-134. doi:10.1016/s0021-9924(99)00002-7

Nijs, S., Penne, A., Vlaskamp, C., \& Maes, B. (2015). Peer interactions among children with profound intellectual and multiple disabilities during group activities. Journal of Applied Research in Intellectual Disabilities, 29(4), 366-377. doi:10.1111/jar.12185

Nijs, S., Schouten, B, \& Maes, B. (2019). Visual functioning of persons with severe and profound intellectual disabilities: observations by direct support workers and staff members and information available in personal files. Journal of Policy and Practice in Intellectual Disabilities. Advance online publication. doi:10.1111/jppi.12316

Nijs S., Vlaskamp, C., \& Maes B. (2015). The nature of peer-directed behaviours in children with profound intellectual and multiple disabilities and its relationship with social scaffolding behaviours of the direct support worker. Child: Care, Health and Development, 42(1), 98-108. doi:10.1111/cch.12295

Nijs, S., Vlaskamp, C., \& Maes, B. (2018). Promoting social scaffolding behaviors in staff members and peer-directed behaviors among persons with profound intellectual and multiple disabilities: An intervention study. Journal of Policy and Practice in Intellectual Disabilities, 15(2), 124-135. doi:10.1111/jppi.12251

OJKO-project. Retrieved from https://ppw.kuleuven.be/ogop/inovho/projecten

Onghena, P., Maes, B., \& Heyvaert, M. (2018). Mixed methods single case research: State of the art and future directions. Journal of Mixed Methods Research, 1-20. doi:10.1177/1558689818789530 
RUNNING HEAD: Methodological challenges and future directions

Palisano, R., Rosenbaum, P., Bartlett, D., \& Livingston, M. (2007). Gross Motor Function Classification System: Expanded and Revised. Child Centre for Childhood Disability Research, McMaster University.

PAMIS. Resources. Retrieved from http://pamis.org.uk/resources/

Pearson, E., Wilde, L., Heald, M., Royston, R., \& Oliver, C. (2019). Communication in Angelman syndrome: A scoping review. Developmental Medicine and Child Neurology, 61(11), 12661274. doi:10.1111/dmcn. 14257

Petitpierre, G., \& Dind, J. (in preparation). Polyhandicap et olfaction [Polyolf]: Montage bottom-up d'une recherche participative et expérimentale. Revue Francophone de la Déficience Intellectuelle

Petitpierre, G., Wolf, D., Adler, J., Benz, M., Dietrich, A. (2007). The integration of education and care given to children with profound multiple disabilities in Switzerland. Journal of Policy and Practice in Intellectual Disabilities, 4(2), 141-151. doi: 10.1111/j.1741-1130.2007.00111.x

Petry, K. \& Maes, B. (2006). Identifying expressions of pleasure and displeasure by persons with profound and multiple disabilities. Journal of Intellectual \& Developmental Disability, 31, 28-38. doi:10.1080/13668250500488678

Petry, K., Maes, B., \& Vlaskamp, C. (2009). Measuring the quality of life of people with profound multiple disabilities using the QOL-PMD: First results. Research in Developmental Disabilities, 30(6), 1394-1405. doi:10.1016/j.ridd.2009.06.007

Platform EMG. Onderzoek \& projecten. [Research \& projects]. Retrieved from https://www.platformemg.nl/onderzoek-projecten/

Poppes, P., van der Putten, A.J.J., \& Vlaskamp, C. (2010). Frequency and severity of challenging behaviour in people with profound intellectual and multiple disabilities. Research in developmental disabilities, 31(6), 1269-1275. doi: 10.1016/j.ridd.2010.07.017

Poppes, P., van der Putten, A.J.J., Post, W., Frans, N., Ten Brug, A., van Es, A., \& Vlaskamp, C. (2016). Relabelling behaviour. The effects of psycho-education on the perceived severity and causes of challenging behaviour in people with profound intellectual and multiple disabilities. Journal of Intellectual Disability Research, 60(12), 1140-1152. doi:10.1111/jir.12299

Rees, K. (2019) Exploring parents' and teachers' conceptualisations of development for young children with S/PIMD. Journal of Intellectual Disability Research, 63(7), 821. doi:10.1111/jir.12661

Research Centre on Profound and Multiple Disabilities. Retrieved from https://www.rug.nl/gmw/pedagogy-and-educational-sciences/research/researchpmd/

Samen Sterker EMB. Retrieved from https://www.zonmw.nl/nl/onderzoek-resultaten/gehandicaptenen-chronisch-zieken/programmas/project-detail/gewoon-bijzonder-nationaal-programmagehandicapten/sterker-samen-vergroten-van-de-kracht-en-welbevinden-van-gezinnen-meteen-persoon-met-emb/ 
RUNNING HEAD: Methodological challenges and future directions

Scelles, R., \& Petitpierre, G. (2013). Polyhandicap: processus d'évaluation cognitive. [Polyhandicap: cognitive evaluation process]. Paris: Dunod.

Simmons, B. \& Watson, D. (2015). From individualism to co-construction and back again: Rethinking research methodology for children with profound and multiple learning disabilities, Child Care in Practice, 21(1), 50-66. doi:10.1080/13575279.2014.976179

Steendam, M. \& Wallroth, M. (2018). Visuele Assessment Schaal Cerebrale Visuele Stoornissen (CVI) bij personen met een zeer ernstige verstandelijke en meervoudige beperking (ZEVMB) Handleiding en invulformulieren. Huizen: Visio.

Sterkenburg, P., Frederiks, K., Barakova, E., Chen, W.M., Peters, P., \& Feijs, L. (2017). A bioresponse system for caregivers of adults with severe or profound intellectual disabilities. Journal of Mental Health Research in Intellectual Disabilities, 10, 121-121. doi:10.1080/19315864.2017.1368259

Tranzo. Retrieved from https://www.tilburguniversity.edu/nl/onderzoek/instituten-enresearchgroepen/tranzo/

Uzgiris, I. C., \& Hunt, J. M. (1975). Assessment in infancy: Ordinal scales of psychological development. Urbana, IL: University of Illinois Press.

Uzgiris, I. C., \& Hunt, J. M. (1987). Infant performance and experience: New findings with the ordinal scales. Urbana, IL: University of Illinois Press.

van den Broek, E. J., van Ramshorst, T., \& Deen, L. (2006). Visual impairments in people with severe and profound multiple disabilities: an inventory of visual functioning. Journal of Intellectual Disability Research, 50(6), 470-475. doi:10.1111/j.1365-2788.2006.00804.x

van der Putten, A.A.J., Dijkstra, R.D., Huls, J.J., \& Visser, L. (2017). Assessment of temperament in children with profound intellectual and multiple disabilities. A pilot study into the role of motor disabilities in instruments to measure temperament. Cogent Psychology, 4(1), 1335038. doi:10.1080/23311908.2017.1335038

van der Putten, A., ter Haar, A., Maes, B., \& Vlaskamp, C. (2015). Duizendpoten: Een literatuuronderzoek naar beschikbare kennis voor zorgprofessionals ten behoeve van de ondersteuning van mensen met (zeer) ernstige verstandelijke en meervoudige beperkingen. [Centipedes: A literature search of available knowledge for healthcare professionals for the benefit of the support of people with profound intellectual and multiple disabilities]. Nederlands Tijdschrift voor de Zorg aan Mensen met Verstandelijke Beperkingen, 41(3), 151-195.

Van keer, I., Ceulemans, E., Bodner, N., Vandesande, S., Van Leeuwen, K., \& Maes, B. (2019). Parentchild interaction: A micro-level sequential approach in children with a significant cognitive and motor developmental delay. Research in Developmental Disabilities, 85, 172-186. doi:10.1016/j.ridd.2018.11.008

Van keer, I., Colla, S., Van Leeuwen, K., Vlaskamp, C., Ceulemans, E., Hoppenbrouwers, K., Desoete, A., \& Maes, B. (2017). Exploring parental behavior and child interactive engagement: A study 
RUNNING HEAD: Methodological challenges and future directions

on children with a significant cognitive and motor developmental delay. Research in Developmental Disabilities, 64, 131-142. doi:10.1016/j.ridd.2017.04.002

Van keer, I., Seghers, N., Van Leeuwen, K., \& Maes, B. (2020). Family activities in families including a young child with a significant cognitive and motor developmental delay: an ecocultural perspective. Journal of Physical and Developmental Disabilities, 32(1), 155-185. doi:10.1007/s10882-019-09688-y

van Timmeren, E. A., van der Putten, A. A. J., van Schrojenstein Lantman-de Valk, H. M. J., Van der Schans, C. P., \& Waninge, A. (2016). Prevalence of reported physical health problems in people with severe or profound intellectual and motor disabilities: a cross-sectional study of medical records and care plans. Journal of Intellectual Disability Research, 60(11), 1109-1118. doi: 10.1111/jir.12298

Van der Weelde, S., \& Bredewold, F. (in preparation). Finding the voice of persons with PIMD: making use of shadowing.

Vandesande, S., Bosmans, G., Schuengel, C., \& Maes, B. (2019a). Young children with significant developmental delay differentiate home observed attachment behaviour towards their parents. Journal of Applied Research in Intellectual Disabilities, 32(1), 106-120. doi: 10.1111/jar.12513

Vandesande, S., Bosmans, G., Sterkenburg, P., Schuengel, C., Van Den Noortgate, W., \& Maes, B. (2019b). Comfort provided by parents versus strangers after eliciting stress in children with severe or profound intellectual disabilities: does it make a difference? Attachment \& Human Development. doi: 10.1080/14616734.2019.1659835

Vandesande, S., Van keer, I., Dhondt, A., \& Maes, B. (submitted). The socio-emotional functioning of young children with a significant cognitive and motor developmental delay.

Visser, L., Vlaskamp, C., Emde, C., Ruiter, S. A., \& Timmerman, M. E. (2017). Difference or delay? A comparison of Bayley-III Cognition item scores of young children with and without developmental disabilities. Research in developmental disabilities, 71, 109-119. doi:10.1016/j.ridd.2017.09.022

Vlaskamp, C. \& Cuppen-Fonteine, H. (2007). Reliability of assessing the sensory perception of children with profound intellectual and multiple disabilities: A case study. Child: Care, Health and Development, 33(5), 547-551. doi:10.1111/j.1365-2214.2007.00776.x

Vlaskamp, C., \& Nakken, H. (2008). Therapeutic interventions in the Netherlands and Belgium in support of people with profound intellectual and multiple disabilities. Education and Training in Developmental Disabilities, 43(3), 334-341.

Vlaskamp, C., Poppes, P., \& Zijlstra, R. (2005). Levensloop in perspectief: Een ondersteuningsprogramma voor volwassenen met zeer ernstige verstandelijke en meervoudige beperkingen. Koninklijke Van Gorcum: Assen.

Vlaskamp, C., Van der Meulen, B. F., \& Smrkovsky, M. (1999). Het Gedragstaxatie-instrument. Groningen: Stichting Kinderstudies. 
RUNNING HEAD: Methodological challenges and future directions

Vos, P., De Cock, P., Petry, K., Van Den Noortgate, W., \& Maes, B. (2010). What makes them feel like they do? Investigating the subjective well-being in people with severe and profound disabilities. Research in Developmental Disabilities, 31(6), 1623-1632. doi:10.1016/j.ridd.2010.04.021

Vos, P., De Cock, P., Petry, K., Van Den Noortgate, W., \& Maes, B. (2013a). Investigating the relationship between observed mood and emotions in people with severe and profound intellectual disabilities. Journal of Intellectual Disability Research, 57(5), 440-451. doi:10.1111/jir.12021

Vos, P., De Cock, P., Petry, P., Van Den Noortgate, W., Maes, B. (2013b). See me, feel me. Using physiology to validate behavioural observations of emotions of persons with severe and profound intellectual disability. Journal of Intellectual Disability Research, 57(5), 452-461. doi: 10.1111/jir.12030

Vugteveen, J., van der Putten, A. A. J., \& Vlaskamp, C. (2014). Inventarisatieonderzoek Mensen met Ernstige Meervoudige Beperkingen: Prevalentie en Karakteristieken. [Inventory Research People with Severe Multiple Disabilities: Prevalence and Characteristics]. Groningen: Stichting Kinderstudies.

van der Putten, A., Vlaskamp, C., Reynders, K., \& Nakken, H. (2005). Children with profound intellectual and multiple disabilities: the effects of functional movement activities. Clinical Rehabilitation, 19(6), 613-620. doi:10.1191\%2F0269215505cr899oa

Warburg, M. (2001). Visual impairment in adult people with moderate, severe and profound intellectual disability. Acta Opthamologica Scandinavica, 79, 450-454. doi:10.1034/j.16000420.2001.790504.x

Ware, J. (Ed.) (1994). Educating children with profound multiple learning difficulties. London: Fulton.

Ware, J. (2004). Ascertaining the views of people with profound and multiple learning disabilities. British Journal of Learning Disabilities, 32(4), 175-179. doi:10.1111/j.1468-3156.2004.00316.x

Wessels, M. D., Paap, M. C. S., \& Van der Putten, A. A. J. (submitted). Look what I can do! The construct validity of an instrument that assesses the functional abilities of people with profound intellectual and multiple disabilities. Journal of Intellectual and Developmental Disability.

Wilderjans, T. F., Lambrechts, G., Maes, B., \& Ceulemans, E. (2014). Revealing interdyad differences in naturally occurring staff reactions to challenging behaviour of clients with severe or profound intellectual disabilities by means of Clusterwise Hierarchical Classes Analysis (HICLAS). Journal of Intellectual Disability Research, 58, 1045-1059. doi:10.1111/jir.12076

World Health Organization (2018). Mental Retardation (F70-F79). In International Statistical Classification of Diseases and Related Health Problems (ICD10). Retrieved from: https://icd.who.int/browse10/2016/en\#/F70-F79.

Young, H., Hogg, J., \& Garrard, B. (2017). Making sense of bereavement in people with profound intellectual and multiple disabilities: Carer perspectives. Journal of Applied Research in Intellectual Disabilities, 30(6), 1035-1044. doi: 10.1111/jar.12285 
RUNNING HEAD: Methodological challenges and future directions

\section{Footnote}

${ }^{1}$ A discussion of the applicability of specific instruments/measures within the target group of persons with PIMD is beyond the scope of this article, specific measures are only mentioned as illustrations. 
RUNNING HEAD: Methodological challenges and future directions

Table 1. Methodological challenges in doing research in persons with PIMD

1. Participant demarcation

Different terminologies

Discussion about core elements of definition

Difficulties in operationalisation and assessment of core elements

2. Participant recruitment

Small sample sizes due to

Low prevalence rates and lack of official PIMD-diagnosis in young children

Health problems causing drop-out

Limited numbers of recruitment channels and oversubscription

Difficulties reaching and motiving families

Underestimation of the learning potential of persons with PIMD

3. Data collection and instruments

Lack of specifically developed and evaluated instruments

Difficulties in applying instruments for typically developing children

Unsuitability of self-report

Unclear validity of proxy report

Problems with reliability and validity of behavioural observations

Fluctuating alertness and attention levels of persons with PIMD

Disruptive factors in daily life situations issues

4. Data analysis

Not always possible to take heterogeneity of the target group into account

Use of non-parametric tests

Reliability and validity of qualitative data analysis

Difficulties in finding an appropriate control group

5. Ethics/Including the 'voice' of persons with PIMD

Challenges in obtaining informed consent of persons with PIMD

Challenges in including the 'voice' of persons with PIMD within the research process

Challenges in including significant others within the research process

6. Theoretical models

Lack of specific theoretical models

Doubts about applicability of general theoretical models

Need for development of adapted/new specific theoretical models 
RUNNING HEAD: Methodological challenges and future directions 